\title{
ANÁLISE DOS VALORES DE FRETE DA SOJA A GRANEL NOS SISTEMAS UNIMODAL E MULTIMODAL DE TRANSPORTE
}

\author{
Rodrigo Oliveira Souza* \\ Camila Pires Cremasco** \\ Luís Roberto Almeida Gabriel Filho***
}

RESUMO: O transporte é o elo entre as unidades produtoras e processoradora dentro do setor do agronegócio, apresenta expressiva participação na economia do país e exige um enorme deslocamento de grandes quantidades de cargas. Contudo, a maioria dos produtos provenientes do agronegócio apresenta baixo valor agregado e alto volume de transporte, como no caso da commodity soja, onde o valor do frete pode se tornar significativo no preço final do produto, sendo relevante identificar os meios e formas de transporte que permitam uma redução nos valores de frete. Dessa forma, o presente trabalho teve como objetivo analisar o transporte da soja de São Simão (GO) a Osvaldo Cruz (SP), visto que a movimentação de soja, entre essas duas cidades, é considerável, em razão de uma ser polo de produção e a outra de processamento da soja, respectivamente, além de possibilitar a comparação entre o transporte unicamente rodoviário com o sistema multimodal. Os dados foram analisados por meio de estatística e simulação, podendo concluir que a multimodalidade na rota analisada permitiria uma redução significativa no valor do frete final de aproximadamente $33,3 \%$, se comparado com o transporte unicamente rodoviário.

PALAVRAS-CHAVE: Frete; Logística; Métodos quantitativos; Transporte multimodal.

\section{ANALYSIS OF FREIGHT RATES FOR BULK SOYBEAN WITHIN THE UNI- AND MULTI-MODAL TRANSPORT SYSTEM}

ABSTRACT: Transport is the link between producing and processing units within agribusiness, featuring an important participation in the country's economy. Although it is the displacement of enormous amount of cargo, most products

Doutorando no Programa de Pós-graduação em Engenharia de Produção da Universidade Federal do Rio Grande do Sul (PPGEP/UFRGS), Rio Grando do Sul, Brasil; E-mail: rodrigo_oliveirasouza@yahoo.com.br

** Faculdade de Ciências e Engenharia, Universidade Estadual Paulista (UNESP), Campus de Tupã, Laboratório de Matemática Aplicada e Computacional.

*** Faculdade de Ciências e Engenharia, Universidade Estadual Paulista (UNESP), Campus de Tupã, Laboratório de Matemática Aplicada e Computacional. 
have low aggregated value and high transport value. This is the case of soybean, a commodity in which freight rates are highly significant in the product's final price. It is very important to identify transport means and ways that reduce freight rates. Current research analyzes transport of soybean from São Simão GO Brazil to Osvaldo Cruz SP Brazil, the former town is a great producer of the commodity and the latter town is a great processer of the same. Research also compares the uni- and multimodal road transport system used. Data were analyzed by statistics and simulation. Results show that the multimodal system, within the route investigated, provides a significant decrease in the final freight rate $(33.3 \%)$ when compared to that in the exclusively road transport.

KEY WORDS: Logistics; Freight; Quantitative methods; Multimodal transport.

\section{INTRODUÇÃO}

A soja é uma das principais commodities agrícolas brasileiras, possuindo expressiva participação no Produto Interno Bruto (PIB). No transporte da soja, os valores de frete podem se tornar significativos na formação do preço final, entre as variáveis está o fato desse produto agrícola apresentar baixo valor agregado.

O transporte rodoviário é mais utilizado no país, no entanto, entre as suas limitações pode-se destacar o elevado custo de frete, quando comparado com as modalidades ferroviária e hidroviária.

No escoamento de produtos agrícolas, as matrizes de transporte hidroviárias e ferroviárias são as mais indicadas, contudo, a infraestrutura férrea e portuária encontra-se, no geral, em péssimo estado de conservação, dificultado o seu uso.

Uma forma de se diminuir os custos com frete seria a utilização da intermodalidade e da multimodalidade, ou seja, usar combinações de modais, quando possível, nos pontos onde se mostram eficientes. Para tanto, é necessário que se estude as exigências dos produtos, pois as variáveis tempo e perdas variam conforme a modalidade.

São utilizadas algumas rotas específicas para a distribuição da soja, entre mercados produtores e processadores. Entre tais rotas pode se destacar o município de São Simão (GO), que configura-se como ponto de escoamento e pertencente a um 
Estado que possui expressiva produção. E a cidade de Osvaldo Cruz (SP) que é um polo processador da matéria-prima soja, tanto da origem de cidades pertencentes a Goiás, como de outros Estados brasileiros.

Tal rota possui uma expressiva movimentação, além de possibilitar a análise da multimodalidade. Dessa forma, o presente artigo teve como objetivo estudar a movimentação de soja de São Simão (GO) a Osvaldo Cruz (SP), verificando por meio da aplicação de métodos matemáticos e estatísticos se com o uso a multimodalidade, ou com a unimodalidade rodoviária, é possível ocorrer uma redução no valor do frete.

\section{MATERIAIS E MÉTODOS}

A pesquisa foi delineada como estudo de campo, já que este tipo de pesquisa permite se aproximar da realidade, conforme Gil (2007) procura aprofundar as questões propostas.

Em fevereiro de 2009, houve uma visita no Porto de Presidente Epitácio (SP), devido o mesmo ter sido utilizado como rota hidroviária, sendo realizada uma entrevista do tipo não-estruturada com o Diretor-Geral responsável pela administração do porto, buscando verificar os entraves para o funcionamento eficiente do porto, o fluxo de carga e suas condições de atender cargas vindas de São Simão (GO) e outras cidades.

Para obtenção de dados relativos ao frete rodoviário, foi usado o banco de dados do Sistema de Informação de Fretes (SIFRECA), devido ao seu teor científico e sempre encontrar-se atualizado pela Escola Superior de Agricultura Luiz de Queiroz (ESALQ) da Universidade de São Paulo (USP).

Para a estimativa do valor a ser cobrado de acordo com a distância na modalidade rodoviária, foi aplicada a técnica estatística de regressão linear simples. Conforme a distância e os fretes negociados em 52 rotas aleatórias, criou-se uma reta de regressão com a finalidade de estimar o valor de frete conforme a distância. A análise para a determinação do valor do frete de acordo com a distância na modalidade rodoviária foi realizada no software estatístico Bioestat 5.0. 
Como pode ser verificado na Figura 1, existe uma relação linear entre a distância $(\mathrm{X})$ e o valor do frete (Y) a ser cobrado, o modelo ajustado pode ser verificado na Tabela 1.

\section{Teste de Regressão Linear}

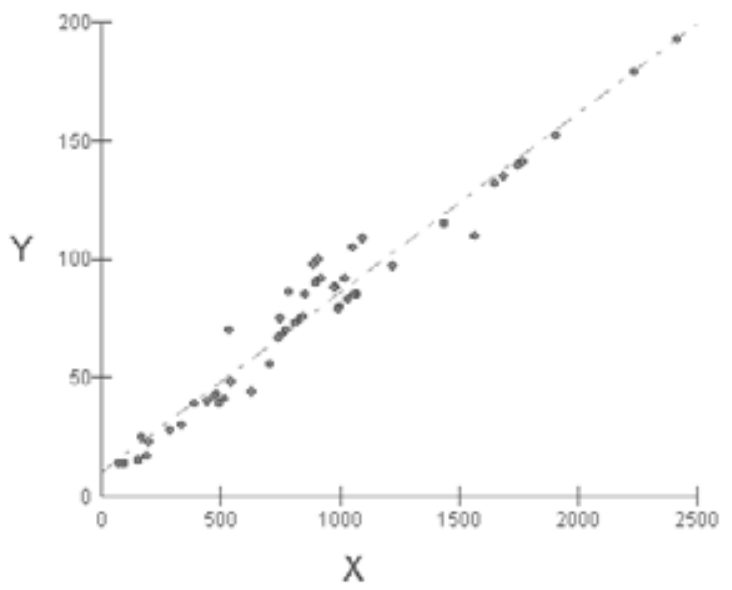

Figura 1. Gráfico de dispersão do valor de frete em relação à distância

Na Tabela 1 foi verificado que existe correlação positiva entre a distância e o valor do frete, o modelo explicaria 95,64\% da variabilidade dos dados.

Tabela 1. Equação da Reta de regressão do frete rodoviário

\begin{tabular}{lc}
\hline $\mathrm{R}^{2}$ (ajustado) & 0,96 \\
\hline Intercepto $(\beta 0)$ & 10,40 \\
Coef. de Regressão $(\beta 1)$ & 0,08 \\
IC $95 \%(\beta 0)$ & 5,70 a 15,11 \\
IC $95 \%(\beta 1)$ & 0,07 a 0,08 \\
\hline
\end{tabular}

Fonte: Dados da pesquisa

Portanto, o valor estimado do frete rodoviário de São Simão (GO) a Osvaldo Cruz (SP), que possui uma distância de aproximadamente $567 \mathrm{~km}$ de acordo com a 
regressão, seria de $\mathrm{R} \$ 53,33$ por tonelada.

Em setembro de 2009 foram aplicados questionários para obtenção de dados, referentes à formação de frete e o panorama da movimentação da soja na matriz de transporte hidroviário, com a empresa transportadora SARTCO que pertence ao grupo ADM, que tem expressiva participação no transporte fluvial na hidrovia TietêParaná e Paraguai-Paraná, onde o porto de Presidente Epitácio localiza-se em sua área de abrangência. $O$ valor de frete considerado foi de $\mathrm{R} \$ 0,025 / \mathrm{t} * \mathrm{~km}$.

$\mathrm{O}$ frete adotado para análise do modal ferroviário foi adquirido com a empresa América Latina Logística (ALL). Devido à sua grande representatividade no transporte nacional de cargas agrícolas com a modalidade ferroviária, além de possuir uma extensa malha férrea e ser responsável pelo trecho que é analisado nesse estudo. $\mathrm{O}$ valor adotado para o frete ferroviário foi definido a partir das tarifas cobradas pela empresa América Latina Logística (ALL), que variam conforme a distância. Até $400 \mathrm{~km}$ o valor é de R\$0,07919 (Ton./Km); de 401 a $800 \mathrm{~km}$ é de R\$ 0,07130 (Ton./Km); de 801 a 1600 km é de R\$ 0,05529 (Ton./Km); de 1601 km em diante, de $\mathrm{R} \$ 0,03924$ (Ton./Km).

Entretanto a ferrovia no trecho de Presidente Epitácio (SP) a Osvaldo Cruz (SP) se encontra paralisado. Desse modo, a pesquisa buscou realizar simulações para estimar quanto seria o frete total caso ocorresse sua utilização.

Em operações multimodais é necessário realizar operação de transporto; no período da pesquisa, o valor do transporto variava em média de $\mathrm{R} \$ 2,00$ (ton), desta forma foi utilizado este valor para realizar as análises.

O presente estudo também buscou estimar um tempo médio de transporte para cada modelo analisado. Para se estimar o tempo de transporte foi utilizada a seguinte função:

$$
V=\frac{S}{t}
$$

onde :

$V=$ velocidade média;

$S=$ distância ou espaço;

$t=$ tempo. 
Adotou-se uma velocidade média constante para cada modalidade, sendo ferroviário de $20 \mathrm{~km} / \mathrm{h}$, hidroviário de $10 \mathrm{~km} / \mathrm{h}$ e rodoviário de $60 \mathrm{~km} / \mathrm{h}$.

Os gráficos de descrição e dispersão da produção da soja foram desenvolvidos pelo software estatístico Minitab 15.0, visto que sua interface gráfica permite obter bons resultados visuais, entretanto, para a elaboração do gráfico de vetores da movimentação na hidrovia, foi utilizado o software SPSS 10.0, por possibilitar a sua personalização de maneira mais prática.

\section{AGRONEGÓCIO DA SOJA}

O agronegócio brasileiro é promissor, pois existem terras em abundância, planas e baratas, clima favorável ao cultivo agrícola, onde faz que o agronegócio tenha notável contribuição na geração de empregos e riquezas para o país.

A soja é uma das principais commodities do Brasil. A área plantada de soja na safra 2008/2009 alcançou 21,7 milhões de hectares, um aumento de 2\% em relação à safra 2007/2008, apesar do crescimento em área houve uma queda de 4,8\% na produção, sendo obtidos 57,1 milhões de toneladas, o que equivale a quase 3.000 milhões de toneladas a menos do que a produção anterior (CONAB, 2009), o que pode ser visto no gráfico de dispersão (Figura 2) da produção nacional de 2001 a 2009.

As perspectivas para 2015 são de que a participação da soja no mercado internacional cresça dos atuais 36\% para 46\%. Vários são os Estados que possuem grande produção de soja, entre eles podemos destacar o Estado de Goiás, que na safra de 2009 apresentou um aumento (Figura 3) em relação à safra do ano anterior, devido aos produtores desse Estado optarem pelo plantio da soja em áreas que seriam de algodão e milho, pelas perspectivas de melhores preços de mercado aliado aos atrasos nas chuvas.

A área plantada neste Estado aumentou em 127,5 mil hectares. Entretanto houve uma redução da média de produtividade por hectare de 1,3\%. Mesmo assim, houve uma produção 4,5\% superior à safra anterior. 


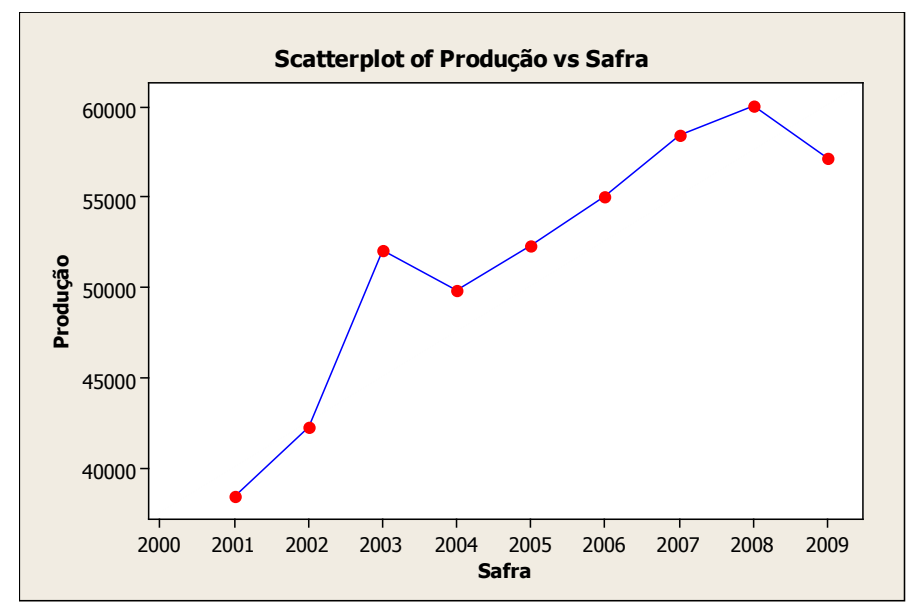

Figura 2. Gráfico da dispersão da produção nacional de 2001-2009 Fonte: Conab (2009), adaptado pelos autores.

A produção nacional (Figura 2), no intervalo de 2001 a 2003, apresentou um crescimento gradativo e em 2004 houve uma queda da produção em torno de 4,47\%, no intervalo de 2004 a 2008 houve crescimento e em 2009 ocorreu novamente uma queda, dessa vez de $4,83 \%$, na produção.

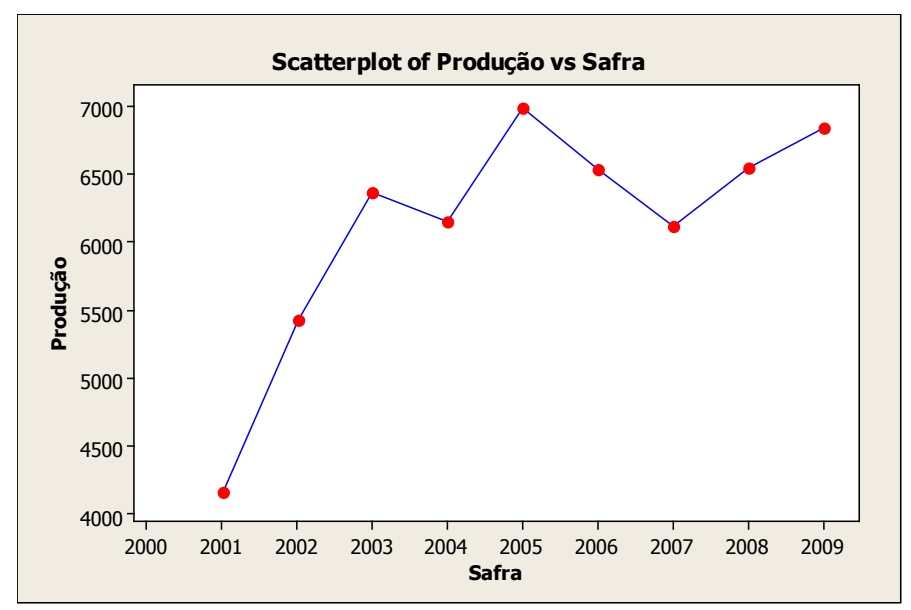

Figura 3. Dispersão da produção de Goiás conforme a safra Fonte: Conab (2009), adaptado pelos autores. 
Na Figura 3 verifica-se que o ano em que o Estado de Goiás apresentou maior produção foi em 2005, aproximadamente 6.895 mil toneladas. A média de produção do Estado é de 6.121,9 mil toneladas com um desvio de 866,7 toneladas.

\subsection{OS SISTEMAS DE TRANSPORTE NO BRASIL}

Um dos desafios para que o agronegócio continue a crescer é a solução dos problemas relacionados à infraestrutura de transporte.

O setor de transportes tem dimensões significativas. Em 2007, o Brasil possuía, segundo Barat et al. (2007), a terceira maior malha rodoviária e a $11^{\mathrm{a}}$ maior malha ferroviária do mundo.

Também segundo os mesmos autores, em grandezas, correspondem a 1,7 milhões de quilômetros de rodovias (9,4\% pavimentadas) e 29 mil quilômetros de ferrovias (com transporte de 345 milhões de toneladas/ano, onde, nesse total apenas $9,4 \%$ de soja e farelo de soja). Em relação às hidrovias, os autores destacam uma pequena participação (20\% do total de rios navegáveis), e em relação à quantidade de portos, têm-se 39 portos e 43 terminais privados, com uma movimentação de 529 milhões de toneladas/ano e 2,3 milhões de contêineres.

Em 2004, o custo logístico no país totalizou $\mathrm{R} \$ 225,6$ bilhões, correspondendo a 12,8\% do PIB e o transporte apresentou um custo de $\mathrm{R} \$ 135,5$ bilhões (BARAT et al., 2007).

No Brasil, a matriz de transporte predominante é o rodoviário, mesmo não sendo indicado para cargas a granel e longas distâncias. $O$ transporte rodoviário é mais eficiente quando utilizado para pequenas distâncias. Dados da Confederação Nacional do Transporte (CNT, 2006) mostram que o modal rodoviário tem predominância no transporte de cargas em torno de $61,8 \%$. As suas principais vantagens são a capacidade de entrega porta-a-porta e o fato de ser um sistema rápido quando comparado com os demais.

Os produtos agrícolas necessitam de maior especificidade para seu deslocamento, onde o modal rodoviário é o mais utilizado, mesmo não apresentando um custo logístico inferior se comparado com o transporte ferroviário e hidroviário.

Um dos fatores que faz com que o valor do frete rodoviário seja maior que os demais é a degradação da malha rodoviária que pode causar aumento nos custos 
operacionais (até 40\%), na despesa com combustíveis (até 60\%) e no tempo das viagens (BARAT et al., 2007, p. 57).

A malha ferroviária apresentou um crescimento lento. Somente na década de 60 chegou a seu auge, possuindo quase $39 \mathrm{mil} \mathrm{km}$. Com o início da privatização das estradas de ferro em 1996, o sistema ferroviário brasileiro desde 1854 oscilou entre fases de crescimento e outras de estagnação. O Brasil possui 29 mil km, sendo que 28,5 mil km estão nas mãos de concessionárias privadas (BARAT et al., 2007).

O modal ferroviário é o indicado como o mais adequado para cargas a granel, mas é limitado ao serviço terminal-terminal e não ponto a ponto. Além disso, a malha ferroviária se encontra abandonada, descontínua e, em alguns trechos, desativada.

Em 2007, de acordo com Pintombo (2008), esta modalidade transportou $28 \%$ de toda a soja do país. A ferrovia é o melhor meio de se deslocar cargas para distâncias entre $500 \mathrm{~km}$ a $1200 \mathrm{~km}$, podendo chegar a ter um custo de transporte $36 \%$ inferior ao rodoviário.

O transporte hidroviário é pouco utilizado para escoamento de cargas no interior do país. A sua maior utilização ocorre em navegações de longo curso. O país utiliza durante o ano apenas $10.000 \mathrm{~km}$ das vias navegáveis na movimentação de cargas, mas a extensão da rede hidroviária pode ultrapassar 40.000 km (CNT, 2006).

A modalidade hidroviária possui uma grande capacidade de escoamento. Estima-se que o custo de transporte por quilômetro em uma hidrovia seja duas vezes menor que o da ferrovia e inferior cinco vezes que a rodovia (CNT, 2006). Um dos motivos da sua pequena participação na movimentação de produtos agrícolas ocorre por possuir um deslocamento lento, em média de $10 \mathrm{~km} / \mathrm{h}$.

De acordo com os dados estatísticos da Agência Nacional de Transportes Aquaviários (ANTAQ, 2009), em 2008, a maior parcela da movimentação de cargas pelo hidroviário foi de granel sólido, com $60 \%$, seguida do granel líquido, com 25\%, e o restante foi movimentado como carga geral, com $15 \%$.

As classificações das maneiras existentes para se transportar produtos no Brasil são definidas como unimodal, intermodal e multimodal. O transporte é considerado unimodal quando se utiliza apenas um modal para levar a mercadoria da origem até o destino. A intermodalidade é considerada quando a carga é 
transportada por mais de um modo, a partir da sua origem até a sua entrega no destino final, com a contratação de um transporte independente em cada uma das etapas. Cada transportador responde isoladamente por sua parcela no trajeto (KEEDI, 2005 apud ANPAD, 2012).

O transporte multimodal é a operação em que a carga é transportada por mais de um modal, sendo realizado por um operador de transporte multimodal (OTM), que assume a responsabilidade por um transporte total, desde a origem até o destino final, é considerado como multimodal quando o contrato de transporte estiver unificando todos os modais utilizados na movimentação da carga, assim como outros serviços, e quando a carga for representada perante o dono por um operador de transporte registrado na Agência Nacional de Transportes Terrestres (ANTT, 2010).

A definição de Operador de Transporte Multimodal pela ANTT (2010) é a seguinte: "[...] pessoa jurídica contratada como principal para a realização do transporte multimodal de cargas, da origem até o destino, por meios próprios ou por intermédio de terceiros", ficando sob a custódia do operador as perdas, danos, atrasos e serviços como armazenagem, movimentação, entre outros. O OTM reduz significativamente os custos de transporte (FARIA; COSTA, 2005).

Várias são as combinações que podem ser formadas, conforme a rota $\mathrm{e}$ principalmente o produto a ser movimentado, com as possíveis combinações entre a origem-destino utilizando os meios de transporte rodoviário (rodo), hidroviário (hidro) ferroviário (ferro).

Segundo Bovolenta (2007), no que se refere a uma maior agilidade e menor burocracia, a multimodalidade mostra-se mais interessante se comparada à utilização de um único modal.

Um estudo realizado por Bravin (2001), utilizando a rota Rio Verde (GO) a Santos (SP), concluiu que com a utilização do transporte multimodal (rodo-hidroferro), há uma economia de 33\% em relação ao frete rodoviário.

De acordo com a rota, época do ano e volume da carga é possível alcançar valores econômicos muito superiores. Por outro lado, conforme as exigências do produto, a multimodalidade pode não ser indicada ou não ocorrer uma redução significativa no valor do frete, pois as variáveis tempo e perdas variam conforme a modalidade. 
Os valores de frete variam conforme o sistema de transporte e a modalidade adotada. Segundo Caixeta-Filho e Gameiro (2001), no mercado de fretes, os preços são formados na livre negociação sem nenhuma interferência do governo. Para Hara (2005), a modalidade de transporte utilizada afetará o preço dos produtos, pontualidade e as condições do produto ao seu destino.

Conforme Barat et al. (2007) o frete corresponde a cerca de $10 \%$ a $15 \%$ do preço final da mercadoria, variando de acordo com o tipo de carga e com o tempo da viagem. De acordo com Caixeta-Filho e Gameiro (2001), a participação do custo com transporte no preço final dos produtos agrícolas no atacado pode chegar a ser duas vezes maior do que dos produtos manufaturados. Na soja, segundo estes mesmos autores, o valor do frete pode ocasionar um aumento de $16,9 \%$ no preço final do produto, pelo fato de ser um produto que possui baixo valor agregado.

\subsection{O PORTO HIDROVIÁRIO DE PRESIDENTE EPITÁCIO (SP)}

De acordo com a Administração do Terminal Portuário de Presidente Epitácio (ATEPPE, 2009), a construção do terminal portuário de Presidente Epitácio (SP) ocorreu na década dos anos 60, incentivada pela movimentação de cargas de gado, madeiras, mate e cereais, provenientes do Mato Grosso do Sul e demais Estados vizinhos. O terminal portuário de Presidente Epitácio, em 1974, era o segundo maior Porto Fluvial do país, perdendo apenas para o de Corumbá (MS). Com a construção da Usina Hidrelétrica Sérgio Motta, e com a formação do lago, o porto teve que ser desativado em 1998.

O terminal portuário é administrado pela ATEPPE, sendo uma autarquia municipal criada em 28 de março de 2003 , através da lei $n^{\circ} 027 / 2003$. O porto não se encontra totalmente equipado devido à pouca movimentação.

Apesar disto, apresenta uma ótima infraestrutura portuária, as instalações da área interna e externa possuem respectivamente capacidade para noventa e cinquenta vagões, já tem o escritório que pode ser utilizado pela Receita Federal, além de iluminação de acesso e de pátio permitindo que ocorram operações vinte e quatro horas por dia, uns dos principais entraves é que possui apenas um elevador para 1400 toneladas/dia. Conforme o Diretor-Geral da ATEPPE, o cais de Presidente 
Epitácio tem condições de ser equipado e atender a todos os tipos de cargas e embarcações.

As ligações com o modal rodoviário ocorrem pelas rodovias SP-270 e BR267, principais rodovias que ligam o Estado de São Paulo com o Mato Grosso do Sul, além de possuir anel viário que permite que a carga chegue a porto sem a necessidade de passar por dentro do município. $\mathrm{O}$ acesso ferroviário se dá pela unidade regional de Presidente Prudente, que é administrada pela concessionária América Latina Logística (ALL), no entanto, encontra-se paralisada devido à má conservação dos trilhos. $\mathrm{O}$ acesso hidroviário ocorre pelo reservatório Sergio Motta do Rio Paraná, sendo de responsabilidade da Administração da Hidrovia Paraná (AHRANA).

Os principais produtos transportados na hidrovia são os grãos e derivados, seguidos por areia e cascalho para construção civil, calcário e fertilizante, mas também madeira, carvão e carne. Em 2009, o total transportado foi de 2.981.587 toneladas de janeiro a julho conforme os dados da AHRANA (2009).

Conforme dados coletados com o gerente da empresa SARTCO, que realiza o transporte na hidrovia Paraná de produtos agrícolas, a empresa movimentou em torno de 200 mil toneladas de soja, ocorrendo um crescimento de $20 \%$ em relação ao mesmo período do ano anterior.

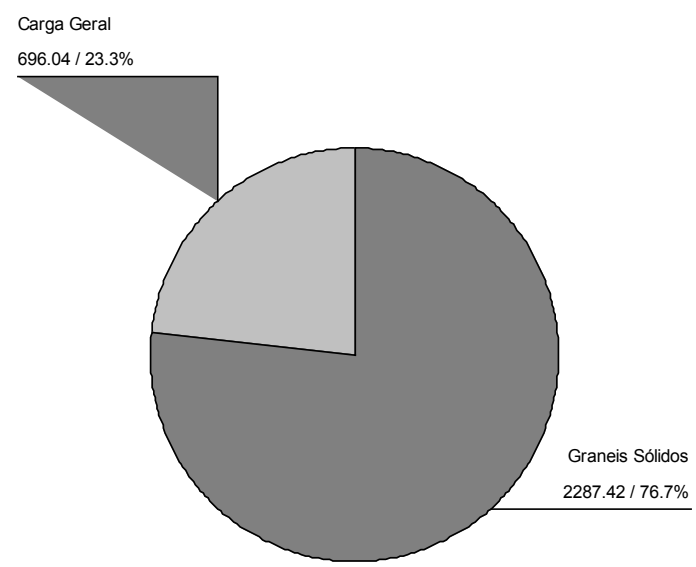

Figura 4. Movimentação na hidrovia Paraná em 2009 (em TKU e Percentual) Fonte: SARTCO (2009), adaptado pelos autores. 
Observando as operações que ocorreram até julho na hidrovia, pode-se perceber que quase $77 \%$ da movimentação foram de granéis, entre eles grande quantidade de soja, e 23\% de outros tipos de cargas (Figura 4).

\section{RESULTADOS E DISCUSSÃO}

Para estudar a movimentação no sistema multimodal comparado com transporte unicamente rodoviário, no trecho de São Simão a Osvaldo Cruz, foram necessárias a criação de simulações, exigindo a estimação dos valores. No modal rodoviário, como já mencionado, foi utilizado o banco de dados da SIFRECA, no período de agosto a setembro de 2009 , época em que a cotação da saca da soja no mercado físico variava entre $\mathrm{R} \$ 38,00$ e $\mathrm{R} \$ 40,00$ a saca de $60 \mathrm{Kg}$, de acordo com a Federação da Agricultura e Pecuária de Goiás (FAEG, 2009).

Na primeira análise, como é mostrada na Tabela 2, utilizou-se um modelo multimodal composto por hidrovia e ferrovia (hidro-ferro), com a soja embarcada no terminal de São Simão (GO), seguindo pela hidrovia em uma distância de 411 km até o Porto de Presidente Epitácio (SP), ocorrendo o transbordo para o modal ferroviário, percorrendo $180 \mathrm{~km}$ até chegar ao destino final, que é Osvaldo Cruz.

Tabela 2. Modelo de multimodalidade hidro-ferro

\begin{tabular}{|c|c|c|c|c|}
\hline Modal & Origem & Destino & $\mathbf{K M}$ & $\mathbf{R} \$ / \mathbf{t}$ \\
\hline Hidroviário & São Simão & Presidente Epitácio & 411 & 10,28 \\
\hline Transbordo & 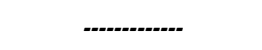 & 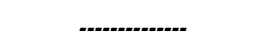 & -..-.-.-. & 2,00 \\
\hline Ferroviário & Presidente Epitácio & Osvaldo Cruz & 180 & 14,25 \\
\hline Total & São Simão & Osvaldo Cruz & 591 & 26,53 \\
\hline
\end{tabular}

Fonte: Elaborada pelos autores

No segundo modelo logístico de análise, como pode ser observado na Tabela 3, foi utilizado um modelo multimodal composto por hidrovia e rodovia (hidro-rodo). A soja foi embarcada no terminal de São Simão (GO) e, a partir daí, seguiu por hidrovia percorrendo uma distância de $411 \mathrm{~km}$ até o Porto de Presidente 
Epitácio (SP), ocorrendo o transbordo para o modal rodoviário, percorrendo 170 $\mathrm{km}$ até chegar ao destino final, Osvaldo Cruz.

Tabela 3. Modelo de multimodalidade hidro-rodo

\begin{tabular}{lcccc}
\hline Modal & Origem & Destino & KM & $\mathbf{R} \$ \mathbf{t}$ \\
\hline Hidroviário & São Simão & Presidente Epitácio & 411 & 10,28 \\
Transbordo & - & - & $-\cdots--$ & 2,00 \\
Rodoviário & Presidente Epitácio & Osvaldo Cruz & 170 & 23,27 \\
Total & São Simão & Osvaldo Cruz & 581 & 35,55 \\
\hline
\end{tabular}

Fonte: Elaborada pelos autores

No terceiro modelo apresentado na Tabela 4, foi utilizado um modelo multimodal composto por rodovia e ferrovia (rodo-ferro). A soja foi embarcada no terminal de São Simão (GO), deslocada pela rodovia em uma distância de 592 $\mathrm{km}$ até o Porto de Presidente Epitácio (SP), ocorrendo o transbordo para o modal ferroviário, percorrendo $180 \mathrm{~km}$ até chegar ao destino final, Osvaldo Cruz.

Tabela 4. Modelo de multimodalidade rodo-ferro

\begin{tabular}{lcccc}
\hline Modal & Origem & Destino & KM & R\$/t \\
\hline Rodoviário & São Simão & Presidente Epitácio & 592 & 55,22 \\
Transbordo & - & - & $-\cdots+\cdots--$ & 2,00 \\
Ferroviário & Presidente Epitácio & Osvaldo Cruz & 180 & 14,25 \\
Total & São Simão & Osvaldo Cruz & 772 & 71,47 \\
\hline
\end{tabular}

Fonte: Elaborada pelos autores

No quarto modelo da Tabela 5 foi utilizada a combinação multimodal de hidrovia, ferrovia e rodovia (hidro-ferro-rodo), saindo a soja do terminal de São Simão (GO), deslocada pela hidrovia, em uma distância de $411 \mathrm{~km}$ até o Porto de Presidente Epitácio (SP), ocorrendo o transbordo para o modal ferroviário, percorrendo $104 \mathrm{~km}$ até Presidente Prudente, ocorrendo o transbordo para o modal rodoviário, percorrendo $84 \mathrm{~km}$ até Osvaldo Cruz. 
Tabela 5. Modelo de multimodalidade hidro-ferro-rodo

\begin{tabular}{|c|c|c|c|c|}
\hline Modal & Origem & Destino & $\mathbf{K M}$ & $\mathbf{R} \$ / \mathbf{t}$ \\
\hline Hidroviário & São Simão & Presidente Epitácio & 411 & 10,28 \\
\hline Transbordo & -..--.-.-. & 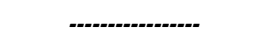 & - & 2,00 \\
\hline Ferroviário & Presidente Epitácio & Pres.Prudente & 104 & 8,24 \\
\hline Transbordo & 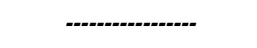 & -...-........-. & 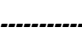 & 2,00 \\
\hline Rodoviário & Pres.Prudente & Osvaldo Cruz & 84 & 16,76 \\
\hline Total & São Simão & Osvaldo Cruz & 599 & 39,28 \\
\hline
\end{tabular}

Fonte: Elaborada pelos autores

No último modelo da Tabela 6 a soja é transportada pelo modal rodoviário da origem de São Simão até o destino de Osvaldo Cruz, em um total de 567 km.

Tabela 6. Modelo rodoviário

\begin{tabular}{lcccc}
\hline Modal & Origem & Destino & KM & R\$/t \\
\hline Rodoviário & São Simão & Osvaldo Cruz & 567 & 53,33 \\
Total & & & 567 & 53,33 \\
\hline
\end{tabular}

Fonte: Elaborada pelos autores

Uma das desvantagens da multimodalidade é o tempo em que o produto fica em trânsito, devido ao deslocamento reduzido dos modais hidroviário e ferroviário.

O estudo não mensurou as variações que podem ocorrer pela infraestrutura logística do país, assim como os tempos de transbordo, pedágios, fiscalização, congestionamentos ou pico de trânsito etc. Podem ocorrer tempos maiores e/ou menores do que os verdadeiros parâmetros praticados.

$\mathrm{Na}$ Tabela 7 é possível verificar o tempo médio estimado de transporte em horas, por cada modelo apresentado. 
Tabela 7. Tempo em trânsito por modelo

\begin{tabular}{cccccc}
\hline & Hidro-Ferro & Hidro-Rodo & Rodo-Ferro & Hidro-Ferro-Rodo & Rodo \\
\hline 41 & 41 & 10 & 41 & 9 \\
& 9 & 3 & 9 & 5 & -- \\
& -- & --- & --- & 1 & -- \\
\hline Total & 50 & 44 & 19 & 47 & 9 \\
\hline
\end{tabular}

Fonte: Elaborada pelos autores

O tempo de transporte com o uso de multimodalidade é superior e significativamente alto do que aquele praticado pela matriz rodoviária.

Através dos valores adotados e das análises logísticas realizadas, foram encontrados resultados significativos no valor do frete final quando utilizada a multimodalidade.

A combinação que se mostra mais viável nesta rota seria hidro-rodo, utilizando a rota São Simão - Presidente Epitácio (hidro) e Presidente Epitácio Osvaldo Cruz (rodo).

A economia seria de 33,3\% em relação ao frete com a combinação multimodal se comparado apenas com a modalidade rodoviária, podendo reduzir ainda mais caso a ferrovia estivesse em funcionamento. Apesar de que esta combinação multimodal apresenta um tempo médio de transporte de 44 horas, onde o que, por meio do transporte unicamente rodoviário, seria em torno de 9 horas.

Podemos verificar nos modelos multimodais criados que apenas o modelo rodo-ferro apresentou um valor de frete $34 \%$ superior se comparado com transporte rodoviário, os demais apresentaram redução. No entanto, podem ocorrer variações superiores ou inferiores em relação ao valor do frete final, pois não foi contabilizado o custo da operação multimodal, que varia de acordo com o contrato estipulado entre o operador e o proprietário da carga, e custo das perdas que cada modalidade pode apresentar. 


\section{CONSIDERAÇÕES FINAIS}

Os sistemas de transporte podem contribuir para o desenvolvimento do país, pois eles impulsionam o crescimento econômico ao movimentar as riquezas nacionais, integralizando áreas produtoras aos mercados consumidores.

Conforme a rota e os dados utilizados nessa pesquisa, pode-se perceber que, com o uso da multimodalidade, é possível reduzir o valor de frete em até 33,3\% se comparado com o sistema de transporte rodoviário. No entanto, a infraestrutura logística da rota em estudo encontra-se em péssimo estado de conservação, dificultando o uso da multimodalidade e sua eficiência na redução dos custos de transporte. Seria imprescindível realizar melhorias na infraestrutura de todos os modais, com destaque para os modais hidroviário e ferroviário que apresentam vantagens tanto econômicas quanto ambientais.

Uma das desvantagens da multimodalidade é o fato de apresentar um tempo de transporte significativamente alto.

Apesar dos entraves, é possivel concluir que a multimodalidade se mostra uma das melhores formas para se reduzir o valor do frete no trecho estudado. Vale ressaltar que o presente estudo não buscou analisar a variável tempo e sua representatividade no valor final do produto, sendo interessante que estudos sejam realizados levando em consideração esta variável e seus reflexos no preço final, assim como as perdas que ocorrem em cada modalidade de transporte.

\section{AGRADECIMENTOS}

Os autores agradecem à Faculdade de Tecnologia de Presidente Prudente (FATEC) pelo suporte científico e estrutural disponibilizado, e ao Conselho Nacional de Desenvolvimento Científico e Tecnológico (CNPq) pela concessão de bolsa de Produtividade em Pesquisa do segundo autor (Processo 306964/2014-7). 


\section{REFERÊNCIAS}

AGÊNCIA NACIONAL DE TRANSPORTES TERRESTRES - ANTT. Disponível em: $<$ http://www.antt.gov.br/carga/multimodal/otm.asp > . Acesso em: 11 jun. 2010.

AGÊNCIA NACIONAL DE TRANSPORTES AQUAVIÁRIOS - ANTAQ. Disponível em: $<$ http://www.antaq.gov.br/Portal/Anuarios/Portuario2008/Index.htm > . Acesso em: 11 ago. 2009.

BARAT, J. (Org.). Logística e transporte no processo de globalização: oportunidades para o Brasil. São Paulo: UNESP: IEEI, 2007.

BOVOLENTA, F. C. Análise energética comparativa na logística de transporte multimodal da soja. 2007. Dissertação (Mestrado em Agronomia/Energia na Agricultura) - Universidade Estadual Paulista, Faculdade de Ciências Agronômicas, Botucatu, SP.

BRAVIN, L. F. N. Análise de transporte multimodal na região da hidrovia TietêParaná. 2001. Dissertação (Mestrado em Agronomia/Energia na Agricultura) Universidade Estadual Paulista, Faculdade de Ciências Agronômicas, Botucatu, SP.

BRAVIN, L. F. N. Logística e transporte na hidrovia Tietê-Paraná: custos e análise ambiental. 2005. Tese (Doutorado em Agronomia/Energia na Agricultura) - Universidade Estadual Paulista, Faculdade de Ciências Agronômicas, Botucatu, SP.

BENEDETTI, M. H. et al. A competição no setor de commodities baseada no uso do transporte intermodal. In: ENCONTRO DA ASSOCIAÇÃO NACIONAL DE PÓSGRADUAÇÃO E PESQUISA EM ADMINISTRAÇÃO, 36., 2012, Rio de Janeiro. Anais... Rio de Janeiro: ANPAD, 2012.

CAIXETA-FILHO, J. V.; GAMEIRO, A. H. (Org.). Sistemas de gerenciamento de transporte: modelagem matemática. São Paulo: Atlas, 2001.

CAIXETA-FILHO, J. V.; GAMEIRO, H. A. Transporte e logística em sistema agroindustriais. São Paulo: Atlas, 2001. 
COMPANHIA NACIONAL DE ABASTECIMENTO - CONAB. Disponível em: < http:// www.conab.gov.br/conabweb/download/safra/1_levantamento_out2008.pdf > . Acesso em: 11 out. 2008.

CONFEDERAÇÃO NACIONAL DO TRANSPORTE - CNT. Disponível em: < http:// www.sistemacnt.org.br/portal/webCanalNoticiasCNT/noticia.aspx?id=9cdc9dffbcad-40b2-b2e6-18bf5e391e46>. Acesso em: 12 set. 2009.

FARIA, A. C.; COSTA, M. F. G. Custo de transporte. In: FARIA, A. C.; COSTA, M. F. G. Gestão de custos logísticos. São Paulo: Atlas, 2005.

FEDERAÇÃO DA AGRICULTURA E PECUÁRIA DE GOIÁS - FAEG. Disponível $\quad$ em: $\quad<$ http://www.faeg.com.br/index.php?option $=$ com content\&view $=$ article\&id $=4335 \&$ Itemid $=111>$. Acesso em: 10 out. 2009 .

GIL, A. Como classificar as pesquisas? In: GIL, A. Como elaborar projetos de pesquisa. São Paulo: Atlas, 2007, p. 41-57.

HARA, C. M. Logística: armazenagem, distribuição e trade marketing. Campinas: Alínea, 2005.

KEEDI, S. Transportes, unitização e seguros internacionais de carga. 3. ed. São Paulo: Lex, 2005.

PINTOMBO, L. H. Agricultura precisa entrar nos trilhos. Rev. Terra Viva, São Paulo, v. 1, n. 4, p. 64-67, out. 2008.

SISTEMA DE INFORMAÇÃO DE FRETES - SIFRECA. Disponível em: < http:/log. esalq.usp.br/sifreca/pt/fretes/rodoviarios/index.php?q= > . Acesso em: 27 set. 2010.

Recebido em: 01 de junbo de 2015 Revisado em:21 de dezembro de 2015 Aceito em: 12 de janeiro de 2016 